\title{
C. difficile hits Sherbrooke, Que., hospital: 100 deaths
}

Published at www.cmaj.ca on Aug. 4, 2004.

Doctors at a Sherbrooke, Que., hospital have lost 100 patients in the last 18 months to Clostridium difficile, the same infection that is dogging wards in Montréal and Calgary hospitals, $C M A 7$ has learned.

In the first 6 months of this year, 46 patients at the Centre Hospitalier Universitaire de Sherbrooke died within 30 days of being diagnosed with $C$. diff $i$ cile-associated diarrhea (CDAD), and 54 patients died in 2003, says Dr. Jacques Pépin, an infectious disease consultant at the hospital and a professor at Sherbrooke University.

He believes this is an underestimate of the actual incidence, calling it "the worst epidemic of hospital-acquired infections that we've had."

"Given that the situation is as bad throughout Montréal and the Montérégie region, it seems likely that before the end of 2004, more than 1000 patients will have died within 30 days of a diagnosis of CDAD in the province of Québec," he says.

In June, $C M A 7$ reported on at least 83 deaths in Montréal and Calgary (CMA7 2004;171[1]:1921), based on the 2003 and 2004 data from some of the affected hospitals. Not all affected hospitals would release data.

Pépin, whose research was early released by $C M A 7$ (see page 466), finds the incidence of

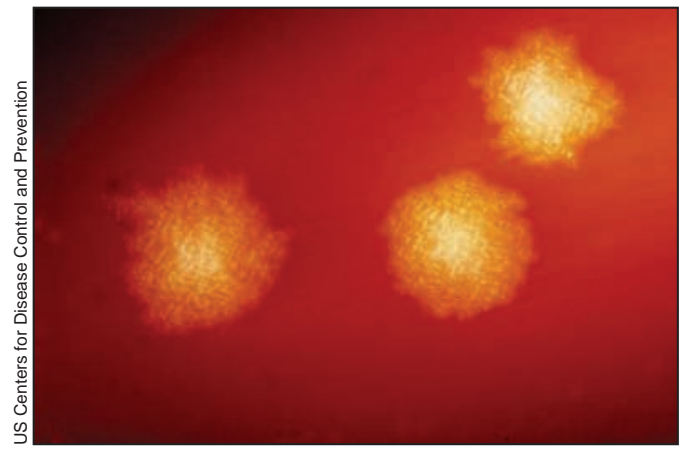

C. difficile, an anaerobic gram-positive rod, is the most frequently identified cause of antibiotic-associated diarrhea, accounting for approximately $15 \%-25 \%$ of all episodes.
C. difficile is also rising. The hospital had 325 cases in the first 6 months of 2004, and 390 cases in 2003 - up from 169 cases in 1991-92.

"If it continues at current rates, incidence rates for 2004 will be roughly double that of 2003," says Pépin, who estimates between $20 \%-25 \%$ of cases were acquired in the broader community.

The infection is not under control in Sherbrooke or Montréal, says Pépin, calling for urgent action from the Quebec Ministry of Health to recognize the outbreak as "a public health emergency." The ministry has formed a committee to investigate. Health Minister Philippe Couillard was not reachable by deadline.

An administrator at the Sherbrooke hospital described the situation as a "crisis." Public health officials and the Quebec ministry should respond faster, says Jacques Poisson, the associate director of professional services. "The measures that were adopted [to combat SARS] were very aggressive compared to what we're doing right now."

Pépin says part of the reason health officials may be reacting less vigorously to the outbreak is because most of those dying are elderly. "There's less reaction than if it had been an outbreak among younger patients."

In 2003, the incidence of the disease in Sherbrooke increased to 156.3 per 100 000, up from 33.2 in 1991. Among individuals aged 65 and older, the incidence has increased 10-fold, from 85 per 100000 in 1991-92, to 866.5 in 2003.

The proportion of people who died within 30 days of diagnosis in Sherbrooke increased to $13.8 \%$ in 2003 , up from $4.7 \%$ in 1991-92. Pépin believes $C$. difficile may be evolving into a more virulent, toxic strain of the disease than physicians previously saw an opinion he shares with Dr.
Cliff McDonald, a medical epidemiologist at the Centers for Disease Control and Prevention.

"Thirty percent or so of [infectious disease] doctors have perceived an increase," McDonald told $C M A 7$. "It seems like the disease is more severe. My gut feeling is that we are having an increase [in incidence and in deaths], that something new is going on."

The CDC hopes to make the link to a new strain of $C$. difficile by testing samples from different geographic locations. It's critical for hospitals to share data to determine the scope of the problem, says McDonald.

$C$. difficile is not a reportable disease in any province or in the US, although Manitoba plans to add it by 2005 .

Pépin and his colleagues at the University of Sherbrooke's Department of Microbiology and Infectious Diseases are calling on the federal government to accelerate research into the extent, causes and treatment of $C$. difficile.

Health Canada should also coordinate a response to the outbreak, through its new Public Health Agency and by involving the national disease control laboratory in Winnipeg, Pépin suggested.

He believes the only longterm solution is to renovate hospitals so patients have private rooms with toilets, or at least improved access to toilets, thereby limiting the spread of infection.

Investing in hospital upgrades would ultimately save money, since it costs $\$ 10000$ to $\$ 12000$ per patient to treat $C$. difficile, Pépin says. By that estimate, it cost more than $\$ 7$ million in Sherbrooke to treat 715 patients in the last 18 months.

"It won't be an easy solution, like giving talks to the nurses and students and residents in terms of hand-washing," says Pépin. "It will take political commitment." Laura Eggertson, CMAJ 